\title{
A RAPID METHOD FOR ESTIMATING THE DEGREE OF MODIFICATION IN BARLEY MALT BY MEASUREMENT OF CELL WALL BREAKDOWN
}

by

\author{
STEN AASTRUP, GREGORY C. GIBBONS and LARS MUNCK \\ Department of Biotechnology, Carlsberg Research Laboratory, \\ Gamle Carlsberg Vej 10, DK-2500 Copenhagen Valby
}

Keywords: Modification, malting, cell wall breakdown, Calcofluor, fluorescence, malt vitreosity

A rapid method to study cell wall breakdown in malt by use of Calcofluor-staining has been developed. Three to five plastic clay plates, each containing 50 half seeds cut longitudinally, can be produced by one person in 20 minutes. The plates are visually evaluated in a newly designed UV-light box. Objective analysis of cell wall breakdown using a television image analyzer is compared with the subjective estimation of modified endosperm. Malt vitreosity and mealyness are compared with cell wall modification on the same set of seeds.

\section{INTRODUCTION}

Recently, a method for visualizing cell wall breakdown in half seeds $(1,6,8)$ or sections of germinating seedlings (5) has been developed. Calcofluor, which specifically binds to $\beta$-glucosidic bonds, was used according to FuLCHER and WoNG (4) using contrast staining with Fast Green F.C.F. to mask nonspecific fluorescence. Hand-cut, stained half-seeds were mounted in modeling clay as described by AASTRUP and ERDAL (1), and evaluated in a specially designed, low-magnification Macrofluorescence Microscope $(6,7)$. Cell wall breakdown has been used in regular malting experiments, the degree of modification being directly measured in a television image analyzer. This procedure is suitable for laboratory work on germination physiology and malting technology, but is too time-consuming for routine analyses in a malt house because each seed has to be cut by hand, and only a limited number of seeds can be evaluated simultaneously under the Macrofluorescence Microscope. In developing a feasible, routine method for measuring malt modification based on endosperm cell wall staining $(1,6,8)$, the following goals have to be met: 
a. A large number of seeds (50-200) should be easily mounted and fixed in a regular pattern for each sample.

b. All seeds should be longitudinally cut, slightly off from the centre of the individual grain.

c. The preparations produced should be easily and quickly stained and dried.

d. An apparatus for visualization should be designed so that one or more of the preparations, each containing 50-200 seeds, can be viewed simultaneously.

e. Preparations should be permanent so that they can be stored together with data from the evaluation as documentation of the quality of malt tested.

A method designed by ALBERs (2) which partly meets these demands uses plastic glue to fix seeds randomly on a glass plate. After hardening the glue at $50^{\circ} \mathrm{C}$ the seeds are longitudinally abraded by a sanding machine. This method has been used to prepare seeds for evaluating vitreosity in malt and barley.

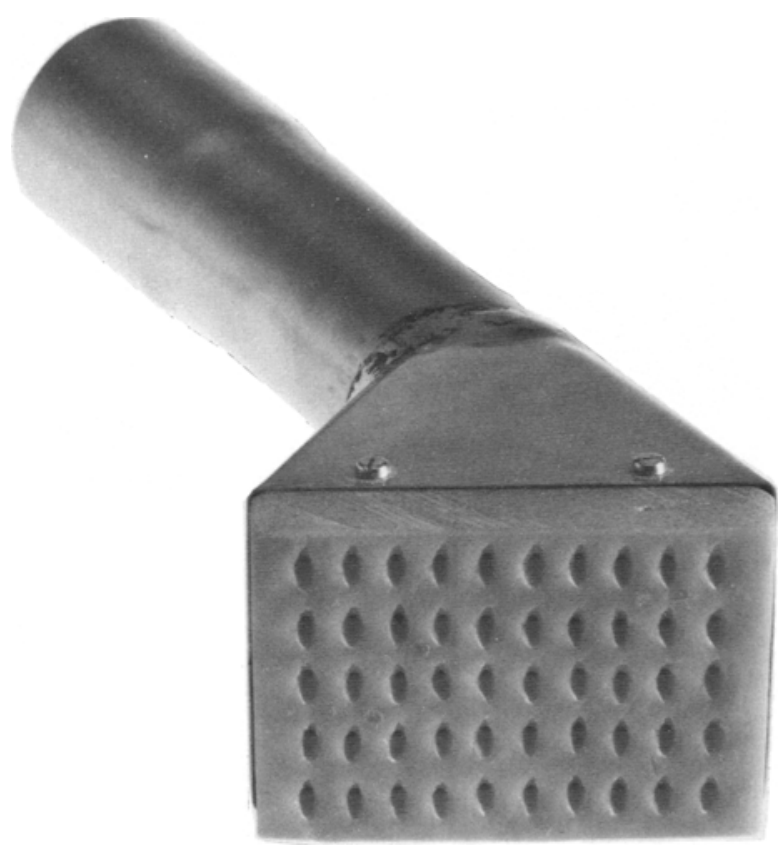

The present communication describes the development of a simple method for preparing samples of 50 seeds and analysing them for the extent of cell wall breakdown by Calcofluor staining as previously described $(1,6,8)$.

\section{MATERIALS AND METHODS \\ 2.1. Plant material}

Kilned malts of the barley varieties Nordal and Minerva at different stages of modification were derived from a pilot malting plant according to the malting procedure described earlier (1). All seeds were greater than $2.5 \mathrm{~mm}$ in diameter.

\subsection{Sample preparation}

\subsubsection{Construction of seed applicator}

A template for 50 seeds $(2.5 \mathrm{~mm})$ was devised. Lateral impressions of a typical malt seed were made 50 times on a $8 \times 80 \times 65 \mathrm{~mm}$ sheet of "Cernit« (T + F GmbH, D-6072 Dreieich, W. Germany), a thermo-plastic, yellow clay. The clay was hardened in a laboratory oven at $160^{\circ} \mathrm{C}$ for $15 \mathrm{~min}$ and $0.5 \mathrm{~mm}$ holes drilled through the Cernit-plate at the deepest part of each seed impression. The plate was then mounted in a stainless steel funnel (Figure 1) attached to a vacuum cleaner.

\subsubsection{Application of malt seeds on plastic clay}

Seeds could easily be sucked on to the template and held in the 50 depressions. The full template was pressed against another sheet of Cernit of equal size (the preparation plate) and the vacuum released. The preparation plate with the seeds was then dried in a laboratory oven for $10 \mathrm{~min}$. at $160^{\circ} \mathrm{C}$ or in a microwave oven for 2 min. Kilned malt was used in the present study. If green malt is to be used in similar studies, it must be dried in a microwave oven before application because drying in a laboratory oven turns the seeds dark before a reasonable dry weight is obtained.

The seeds, randomly oriented perpendicular to their longitudinal axis (Figure 4), were securely fastened by the hardening process in preparation for the following abrasive treatment.

Figure 1. Seed applicator with template. 


\subsection{Sanding of the preparations to obtain half seeds}

The sample plate was mounted horizontally in a vice and abraded by a normal sanding machine (Black and Decker) (Figure 2), slightly to the side of the longitudinal axes of the seed so that the maximum cross section of the seeds (Figure $4 b$ ) was exposed.

\subsection{Staining of the preparations}

The whalf seeds" were stained for $30 \mathrm{sec}$. by dropping on $0.1 \%$ aqueous Calcofluor TM White M2R (Cyanamid, USA) followed by washing in $70 \% \mathrm{v} / \mathrm{v}$ aqueous ethanol and drying in a stream of air. The preparation was then counterstained with $0.1 \%$ aqueous Fast Green F.C.F. (Gurr/Searle, England) for $30 \mathrm{sec}$. followed by blotting with a paper tissue to remove excess dye. The seed preparation (Figure 4) was dried at room temperature before being preserved by application of a thin layer of nail polish.
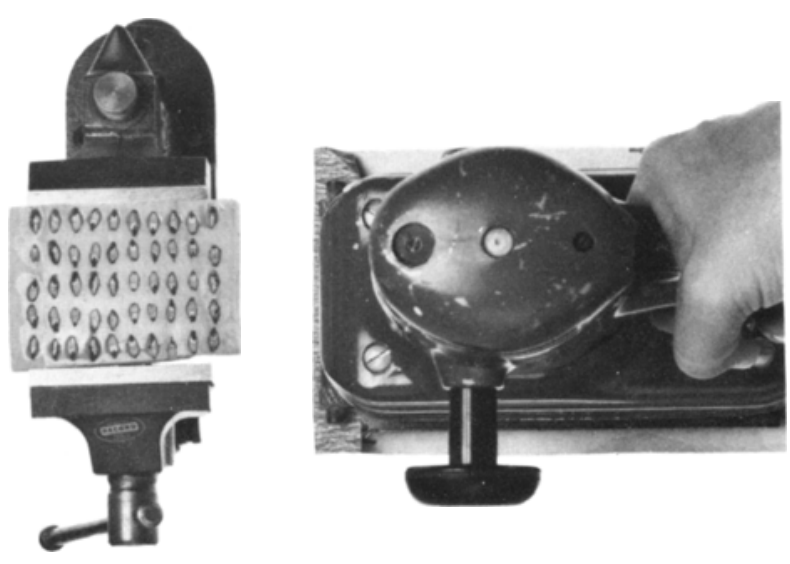

Figure 2. Abrading the seeds cast in the preparation plate with a sanding machine.

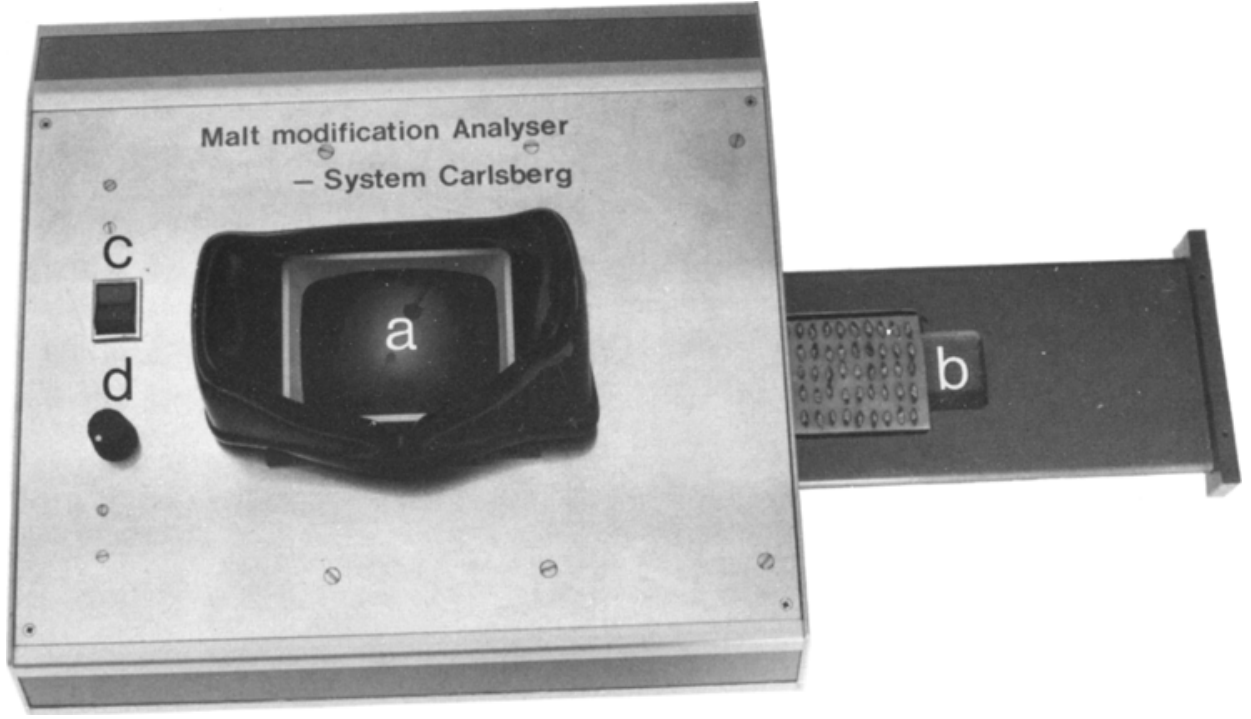

Figure 3. Malt Modification Analyser.

a) Viewer, b) sample holder with preparation plate. c) main switches for UV and visible light, d) intensity control knob for visible light. 
으
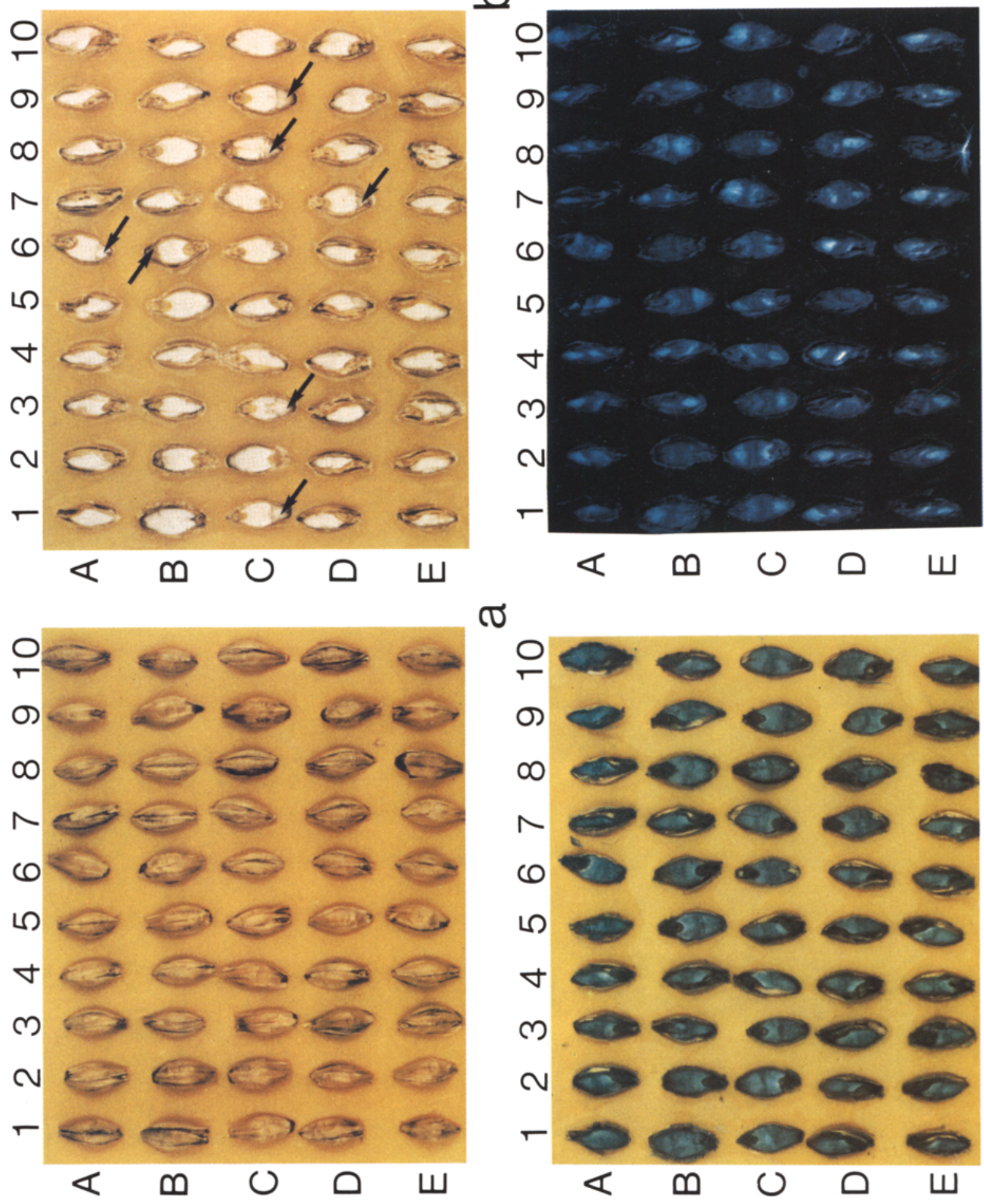

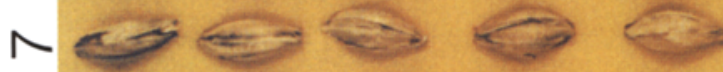

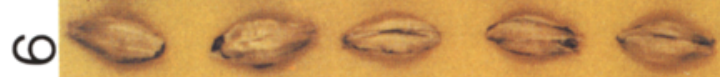

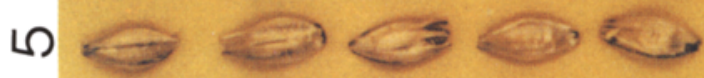

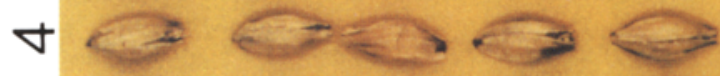

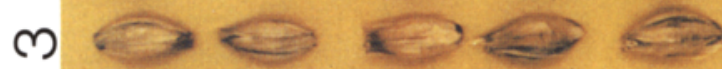
N $\Leftrightarrow+3 x+3$

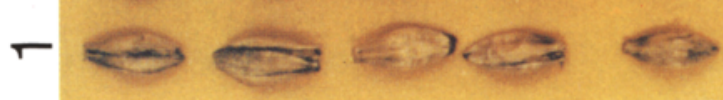
$\varangle \quad \infty \quad \cup \quad \square$ 

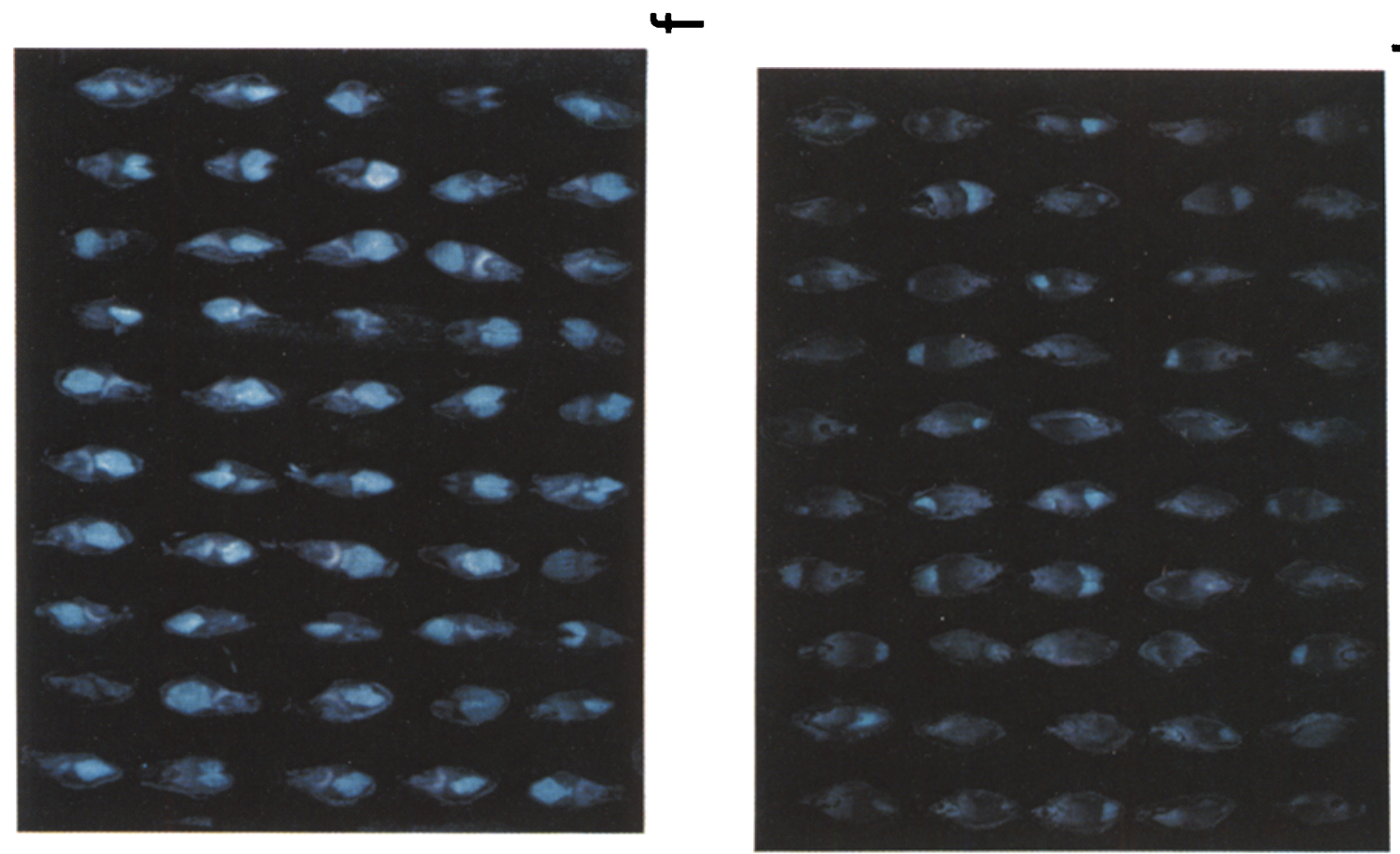

(1)
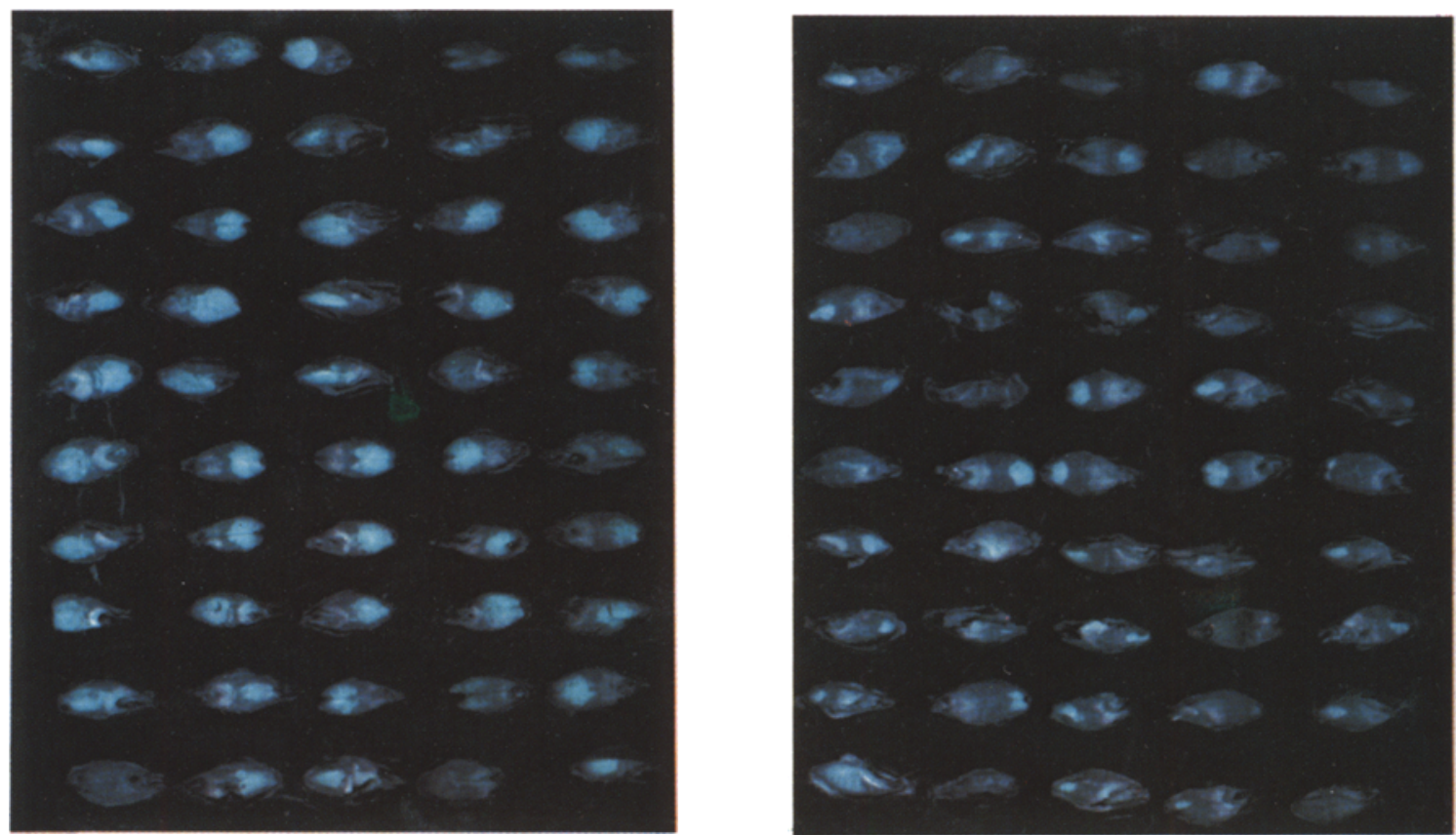

Figure 4. a) - d) Sample preparation procedure illustrating identical seeds from different treatment steps for kilned Nordal malt ( 8 days malting).

a) Whole seeds attached to plate, b) plate after abrasion, c) stained seeds in normal light, d) stained seeds in UV-light. $\mathrm{M}_{50}=76.7 \pm 4.0$ (see Table I).

e) - h) Stained seeds as seen in UV-light. Samples are from kilned malts of different degrees of endosperm cell wall modification (see Table I).

e) Minerva ( 6 days malting) $\mathrm{M}_{50}=48.8 \pm 3.2, \quad$ f) Minerva $\left(8\right.$ days of malting) $\mathrm{M}_{50}=60.6 \pm 3.2, \mathrm{~g}$ ) Nordal ( 10 days of malting) $\mathrm{M}_{50}=83.0 \pm 3.7, \quad$ h) Nordal ( 14 days of malting) $\mathrm{M}_{50}=90.9 \pm 2.8$. 


\subsection{Malt Modification Analyser (Figure 3)}

The Malt Modification Analyser, designed according to Munck, Feil and Gibbons (9), consists of a box with a light source for long UV-light $(366 \mathrm{~nm})$ as well as a normal light source which can be regulated to obtain a weak background illumination. The seed preparation is introduced in the box on a slide holder at the side of the box and viewed at a slight magnification $(1,5 x)$ through a rectangular viewer. Figures $4 \mathrm{~d}-4 \mathrm{~h}$ show fluorescent preparations visualized by UV-light in the analyzer.

\subsection{Television image analysis to quantify the degree of modification}

Television image analysis was performed as previously described (1). Modification percentage of an individual seed $\left(\mathrm{M}_{\mathrm{i}}\right)$ was calculated as modified area in percent of the whole endosperm area in a median longitudinal section of the seed. Average modification percentage $\left(\mathrm{M}_{50}\right)$ in a preparation of 50 seeds was calculated $\left(\mathrm{M}_{50}=\right.$ $\left.\Sigma \mathrm{M}_{\mathrm{i}} / 50\right)$ as well as standard deviation of distribution(s) and $95 \%$ confidence limits of average $\left(\mathrm{M}_{\mathrm{a}} \mp 2 \mathrm{~s} / \sqrt{50}\right)$.

\subsection{Visual determination of modification}

The modification percentage was judged visually in the Malt Modification Analyser by comparing individual seeds with a standard set of whalf seeds" with $\mathrm{M}_{\mathrm{i}}=10,20,40,60,80$ and $90 \%$ previously measured in the image analyzer (1).

\section{RESULTS AND DISCUSSION}

Different morphological criteria indicative of the degree of malt modification have been described in the literature. These include the acrospire length, endosperm vitreosity (2), appearence of the endosperm following warm water washing $(10)$ and cell wall breakdown as indicated by specific staining $(1,3,5,6,8)$. Drawings, but to our knowledge no photographs, have been published with a description of the modification process based on cell wall staining with Congo Red (3). In our experience Calcofluor counter-stained with Fast Green F.C.F. gives much clearer preparations $(1,5)$ in the study of barley malt than does Congo Red. Using Calcofluor/Fast Green F.C.F. it was shown (1) that the degree of modification could be quantified either by television image analyzer or by visual comparison to a standard. In that study, preparation of a representative sample ( 50 seeds) took about $30 \mathrm{~min}$. and evalutation in the microscope almost as long.

\subsection{Sample preparation}

The new technique described in this paper speeds up the preparation procedure of the earlier method $(1,6)$ by $5-10$ times. In the laboratory 3-5 samples of 50-200 seeds may be prepared within 20 min and can then be used for the study of vitreosity of barley or malt and for further staining of the cell wall components. The hardened plastic plate is resistant to breakage and can be kept on file as a document of malt quality. The stained plate can be preserved by a thin layer of nail polish.

In Figures $4 a-4 d$ different stages in the preparation of 50 seeds of kilned, Nordal malt (8 days of malting at $15^{\circ} \mathrm{C}$ ) are illustrated in photographs: a) after application to the preparation plate $-b$ ) after sanding - c) after staining as seen in normal light and - d) after staining as seen in UV-light.

The seeds are seen to be randomly oriented during application to the plate (Figure 1) with regard to their rotation perpendicular to the longitudinal axis. For example, in Figures $4 a-$ 4d, 24 seeds are pointing with embryos upwards and 26 downwards. A-2, A-4 and D-5 are cut laterally while D-9 and C-8 have the dorsal side towards the plastic. The influence of this random seed orientation on seed modification measurements as compared with seeds cut evenly and placed laterally by the earlier method $(1,6)$ will be discussed in section 3.3

\subsection{UV-visualization of cell wall breakdown}

The sample plates ( 50 seeds) are viewed one by one in the Malt Modification Analyser (Figure 3) as described in section 2.6 at a slightly increased magnification $(\times 1.5)$. It is also possible with a similar arrangement to inspect and compare simultaneously several $(5-10)$ plates to obtain a convenient ranking of the degree of cell 
wall modification between different malts. The new technique allows for a much faster visual evaluation compared to the old technique $(1,6$, 7) where only a limited number of seeds could be inspected at a time. The visual impression obtained with the Malt Modification Analyser is crisp and easy to interpret, regions with unmodified cell walls standing out with an especially intense, light-blue fluorescence. In Figure 4, preparations from five malts (d-h) with different degrees of modification are shown as photographed in UV-light. The degrees of modification $\left(\mathrm{M}_{50}\right)$ calculated by the television image analyzer are given in the text to Figure 4 and in Table I. It is seen that unmodified endosperm cell walls remain in the distal parts of the seeds. This is easily recognized in test-samples $4 a-4 d$ where the position of each seed can be easily identified in photographs of the sample preparation process $(4 a-4 c)$. In Figure $5 b$ the three seeds B4-B6 of Figure $4 \mathrm{~d}$ are enlarged to clearly illustrate the differences. B6 represents a totally modified seed with no fluorescent endosperm cell walls. Seed B-4 has a small part (19.4\%) of the distal tip unmodified while seed B-5, with its distal part pointing downwards, has a larger unmodified part $(25,8 \%)$ as measured by the television image analyzer.

Figure $5 \mathrm{~b}$ points out other structures (marked with arrows) which also show fluorescence; parts of the embryo and scutellum (especially the epithelial layer) binds Calcofluor, presumably due to $\beta$-glucosidic linkages from cellulose. As seen directly in the Malt Modification Analyser these structures are much less intense in fluorescence compared with the unmodified endosperm cell walls. On colour photographs, however, the distinction between embryo/scutellum fluorescence and endosperm cell wall fluorescence is not always obvious in low magnification, particularly if it is difficult to identify the morphological components (compare Figure $5 \mathrm{~b}$ with Figure $4 \mathrm{~d}$ seeds B4-B6). Nevertheless, as seen in Figures $4 d-4 h$, the colour photos give an impression of the endosperm cell wall modification which match the values obtained using the television image analyzer.

\subsection{The problem of seed orientation and the plane of abrasion in relation to cell wall modification measurement}

GibBons has analysed cell wall breakdown in a three dimensional study of germinating barley (5). In the first three days of modification at $15^{\circ} \mathrm{C}$, scutellum dissemination of cytolytic enzymes predominates and a zone of modification parallel to the scutellar epitheleum spreads through the endosperm. On the third day and later, cell wall breakdown is seen adjacent to the aleurone layer starting in the areas proximal to the scutellum. This breakdown then spreads to the more distal parts of the seed, encircling an unmodified "plug" in this end of the seed. It can thus be anticipated that a longitudinal, off-center section of a seed stained with Calcofluor/Fast Green F.C.F. will show a higher modification percentage than if the cut had been through the centre of the unmodified "plug«. Successive sandings and stainings of several samples confirmed that there is a minimum of apparent modification in the centre of the seed.

In Table I, television image analyzer measurements of the malt samples with free orientation as shown in Figures $4 \mathrm{~d}-4 \mathrm{~h}$ are compared with the earlier preparation method $(1,6)$ where the lateral side is exposed. The error of the television image analysis operation is less than $1 \%$ (1). With regard to sampling from a pilot malting batch of 16 kilograms of barley, samples of 50 seeds were found to be sufficient, provided they were randomly sampled. T-tests showed no significant differences between duplicate measurements (1).

It is seen in Table I that there is agreement between determinations of endosperm cell wall modification $\left(\mathrm{M}_{50}\right)$ from samples with constant and random seed orientation although the latter tends to show a higher modification percentage.

The malt analyzed in these investigations was derived from barley samples having a seed size above $2.5 \mathrm{~mm}$. If smaller seeds are to be analyzed it is recommended that they be isolated as a separate fraction and that a specially designed template be used in order to get the abrasive plane as near the longitudinal axis as possible. By initially cutting the plastic clay sheets to a uniform thickness and by supplying the template with four distance needles in the corners it should be possible to optimize the 
Table I

The effect of seed orientation on modification and comparison between television image analyzer measurements and subjective estimations.

\begin{tabular}{|c|c|c|c|c|c|c|c|}
\hline \multirow[b]{3}{*}{ Variety } & \multirow{3}{*}{$\begin{array}{l}\text { Days of } \\
\text { malting }\end{array}$} & \multicolumn{6}{|c|}{ Average Modification (\%) } \\
\hline & & \multicolumn{2}{|c|}{$\begin{array}{l}\mathrm{M}_{50} \text { Image analyser } \\
\text { Orientation of seeds }\end{array}$} & \multicolumn{4}{|c|}{$\begin{array}{l}\text { M50 Subjective estimation } \\
\text { on randomly oriented material }\end{array}$} \\
\hline & & lateral & random & A & $\mathrm{L}$ & M & (persons) \\
\hline Nordal & 8 & $68.7 \pm 4.7$ & $76.7 \pm 4.0$ & $74.1 \pm 5.0$ & $76.6 \pm 4.2$ & 81.8 & \pm 3.4 \\
\hline Nordal & 10 & $83.8 \pm 4.3$ & $83.0 \pm 3.7$ & $88.0 \pm 4.1$ & $85.7 \pm 4.0$ & 81.9 & \pm 5.6 \\
\hline Nordal & 14 & $86.4 \pm 3.6$ & $90.0 \pm 2.8$ & $86.7 \pm 3.5$ & $88.8 \pm 2.9$ & 90.9 & \pm 2.5 \\
\hline Minerva & 8 & $41.8 \pm 2.3$ & $48.8 \pm 3.2$ & $35.9 \pm 5.0$ & $31.3 \pm 3.6$ & 35.6 & \pm 6.3 \\
\hline Minerva & 10 & $54.6 \pm 3.7$ & $60.6 \pm 3.2$ & $46.9 \pm 4.5$ & $45.0 \pm 6.0$ & 51.9 & \pm 5.0 \\
\hline
\end{tabular}
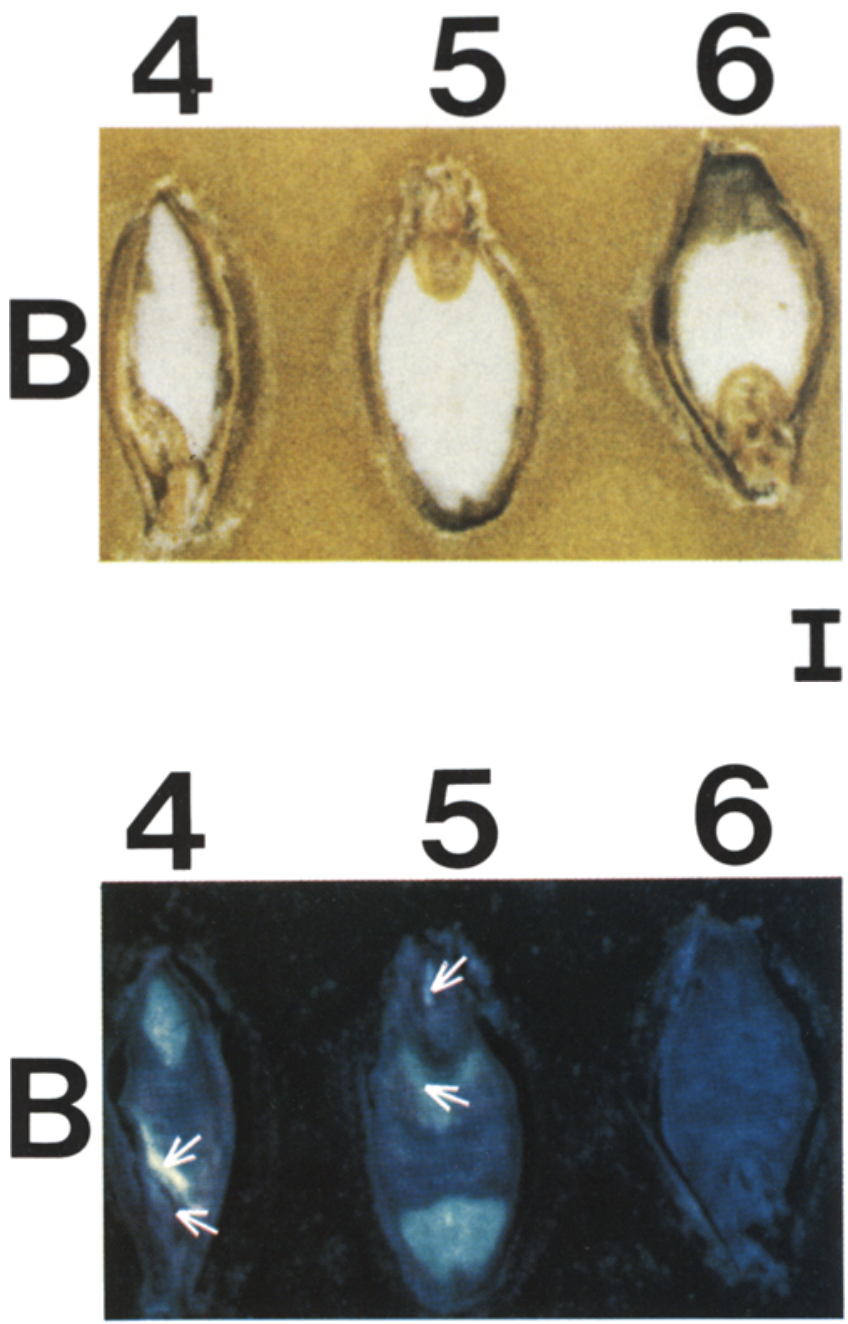

sample preparation conditions so that seeds are immersed approx. half their diameters in the Cernit preparation plate. The sanding machine is then used to abrade the seeds just until contact is made with the preparation plate. This ensures the best reproducible central cut.

\subsection{Visual estimation of cell wall breakdown}

The use of a television image analyzer for quantification of endosperm cell wall breakdown is limited by the high cost of the equipment. As a more economic alternative, a manual method of estimation was introduced. The accuracy of this visual estimation of malt preparations was tested using a procedure described earlier (1). After a training period of $30 \mathrm{~min}$ on known material, test persons estimated the degree of modification of individual seeds as viewed in the Malt Modification Analyser (Figures 3, 4d-4h) compared to a standard set of seeds. Mean modification $\left(\mathrm{M}_{50}\right)$ and statistics are presented in Table I. It is seen that subjective visual estimation of cell

Figure 5. Enlargements of seeds B4-B6 in Figures $4 b$ and $4 \mathrm{~d}$.

a) Unstained sanded seeds. b) Seeds stained with Calcofluor/Fast Green and photographed in UV. light. Arrows point to fluorescence from Calcofluor stained structures of scutellum and embryo to be distinguished from fluorescence of $\beta$-glucan contained in the intact endosperm cell wall. Endosperm modification as measured with the television image analyzer: $\mathrm{B} 4=80.6 \%, \mathrm{~B} 5=74.2 \%$ and $\mathrm{B} 6=$ $100 \%$. 
wall modification yields a good ranking of malt samples when compared with results from the television image analyzer. There is, however, a tendency to underestimate the degree of modification of the least modified samples. It is expected that more intense and regular training would considerably improve the accuracy of the visual estimation.

\subsection{Comparison with other methods for malt modification}

Albers (2) used the sanding method to abrade malt seeds to study the degree of vitreosity in malt. According to ALBERs, complete vitreosity is caused by barleys with very weak or no enzymatic activity. The vitreosity noted in the middle and the edge of the grain is due to $» \mathrm{kil}-$ ning vitreosity« which is attributed to the speed at which water is extracted from the seed during kilning. Completely modified seeds sometimes show a creamy appearance due to partial saccharification and possible caramelisation during kilning.

Figures $4 \mathrm{~b}$ and $4 \mathrm{~d}$ allowed for a comparison in individual seeds of vitreosity and mealy appearance on one hand and cell wall modification on the other. As seen in Figure 4b, an overkilned »creamy « seed (E-8) is, in fact, completely modified (Figure 4d). Vitreous parts of unstained, abraded seeds are marked with arrow for seeds A-6, B-6, C-3, C-8, C-9 and D-7 and the corresponding cell wall modification pictures can be seen in Figure 4d. It is clear in most cases that the vitreous tip is coincident with an unmodified endosperm cell wall area which is, however, generally smaller than the vitreous area. Furthermore, the completely modified seed B-6 (Figures $4 \mathrm{~b}, 4 \mathrm{~d}$ and $5 \mathrm{I}, 5 \mathrm{II}$ ) has a vitreous tip which is probably an example of »kilning vitreosity «. From the foregoing it is clear that the vitreosity of malt gives an estimate of malt modification, but that the criterion is not as clear or as well defined as the cell wall modification criterion. It is also clear that mealyness in itself is not a guarantee of complete cell wall modification. Unmodified endosperm parts are abundantly seen in mealy areas as exemplified by seeds B-4 and B-5 in Figures 4b, 4d and enlarged in Figures 5 I and 5 II.

In an earlier study (8) we have examined
PaLmer's (10) warm water treatment of longitudinal, ventrodorsal sections of seeds. This washing technique extracts starch and leaves a dorsal cavity in the cut surface. The more modified the seed, the larger is the dorsal cavity. Investigations on seeds extracted according to PALMER with Calcofluor/Fast Green F.C.F. staining reveals modified areas in parts where starch was not extracted with the washing technique. It is clear that the two methods study different concepts of modification which may both have relevance as indicators of malt modification. The wider biochemical significance of the cell wall modification method has been demonstrated by GiBbons (7), whose work with specific fluorescent antibodies of $\alpha$-II-amylase showed that the enzyme spreads approx. at the same rate and in the same morphological pattern as the cell walls degrade. Thus, on the same sections of germinating seeds, areas of cell wall breakdown and $\alpha$-II-amylase activity almost coincide. A recent study (1) showed high correlation between endosperm modification and the $\beta$-glucan content of malt, indicating a close relationship between modification and hydrolysis of $\beta$-glucans. In that study, however, the traditional estimate of malt modification, acrospire lenght was poorly correlated with cell wall modification of the endosperm.

Endosperm modification measured as the percentage of residual endosperm cell wall seen in a longitudinal section, is thus a convenient and informative measurement of malt modification from the morphological and biochemical point of view. The technique described in this communication will enable a more extensive testing in the malthouse and the laboratory. Investigations to compare cell wall breakdown with corresponding malt, wort and beer analyses on a pilot scale and in process plants are in progress.

\section{ACKNOWLEDGEMENTS}

The authors are indebted to Ms. Mette Høj for the photographic work and to Ms. LisBETH JENSEN for technical assistance. The help of Mr. Martin Max Nielsen in building the prototype of the Malt Modification Analyser and of Ms. BrItha Jensen in typing the manuscript is also gratefully acknowledged. Mr. JoHN MUNDY kindly helped us with the correction of the manuscript. 


\section{REFERENCES}

1. Aastrup, S. \& K. Erdal: Quantitative determination of endosperm modification and its relationship to the content of 1,3:1,4- $\beta$-glucans during malting of barley. Carlsberg. Res. Commun. 45, 369-379 (1980)

2. Albers, V. J.: Improved method for the determination of vitreosity in malt. Brewers Digest. 55 (8), 38-39 (1980)

3. Briggs, D. E.: Barley. Chapman and Hall, London 9-14, pp 612 (1978)

4. Fulcher, R. G. \& S. I. Wong: Inside cereals: A fluorescence microchemical view. Proc. Intl. Conf. Cereals for Food and Beverages, Acad. Press, New York, pp 1-26 (1980)

5. Gibmons, G. C.: On the sequential determination of $\alpha$-amylase transport and cell wall breakdown in germinating seeds of Hordeum vulgare. Carlsberg Res. Commun. 45, 177-184 (1980)
6. GibBons, G. C.: Visualization of $\alpha$-amylase transport and cell wall breakdown during malting of barley. Journal of the American Society of Brewing Chemists. In press (1981)

7. Gibbons, G. C. \& L. Munck: Swedish patent application No 790491-1 (1979)

8. Gibbons, G. C., S. Aastrup \& L. Munck: Rapid visualisation of cell wall breakdown and $\alpha$ amylase transport during malting of barley. EBC Symp. on the relationship between malt and beer, Helsinki, Finland 4-5 November 1980 (1980)

9. Munck, L., C. Feil \& G. C. Gibmons: Swedish patent application No 7811307-3 (1978)

10. Palmer, G. H.: A method for direct assessement of malt modification. J. Inst. Brew. 81, 408-409 (1975) 